\title{
A novel approach for the extraction of cloud motion vectors using airglow imager measurements
}

\author{
S. Satheesh Kumar, T. Narayana Rao, and A. Taori \\ National Atmospheric Research Laboratory (NARL), Gadanki, India \\ Correspondence to: T. Narayana Rao (tnrao@narl.gov.in)
}

Received: 11 February 2015 - Published in Atmos. Meas. Tech. Discuss.: 12 March 2015

Revised: 14 August 2015 - Accepted: 27 August 2015 - Published: 23 September 2015

\begin{abstract}
The paper explores the possibility of implementing an advanced photogrammetric technique, generally employed for satellite measurements, on airglow imager, a ground-based remote sensing instrument primarily used for upper atmospheric studies, measurements of clouds for the extraction of cloud motion vectors (CMVs). The major steps involved in the algorithm remain the same, including image processing for better visualization of target elements and noise removal, identification of target cloud, setting a proper search window for target cloud tracking, estimation of cloud height, and employing 2-D cross-correlation to estimate the CMVs. Nevertheless, the implementation strategy at each step differs from that of satellite, mainly to suit airglow imager measurements. For instance, climatology of horizontal winds at the measured site has been used to fix the search window for target cloud tracking. The cloud height is estimated very accurately, as required by the algorithm, using simultaneous collocated lidar measurements. High-resolution, both in space and time ( $4 \mathrm{~min}$ ), cloud imageries are employed to minimize the errors in retrieved CMVs. The derived winds are evaluated against MST radar-derived winds by considering it as a reference. A very good correspondence is seen between these two wind measurements, both showing similar wind variation. The agreement is also found to be good in both the zonal and meridional wind velocities with RMSEs $<2.4 \mathrm{~m} \mathrm{~s}^{-1}$. Finally, the strengths and limitations of the algorithm are discussed, with possible solutions, wherever required.
\end{abstract}

\section{Introduction}

Clouds play a vital role in the Earth's hydrological cycle and also as "atmospheric blankets" because of their shortwave scattering and longwave absorption of radiation. It is, therefore, highly essential to monitor the clouds and their motion on a continuous basis, which is being done primarily by geostationary meteorological satellites (Leese et al., 1971; Hutchison et al., 1995; Jolivet and Feijt, 2003; Glantz, 2010; Escrig et al., 2013). The capability of continuous monitoring of clouds by these satellites has been utilized to retrieve the cloud motion vectors (CMVs), by considering clouds as tracers of wind. Satellite-derived CMVs are extremely helpful in understanding synoptic-scale atmospheric dynamics and circulations and now have become potential input parameters to numerical weather prediction models (Menzel, 2001; Thies and Bendix, 2011 and references therein).

There is a tremendous progress in retrieval techniques for CMVs and their utilization for operational usage in the last few decades. The retrieval techniques improved from a simple cross correlation analysis in the beginning (Izawa and $\mathrm{Fu}-$ jita, 1969; Leese et al., 1971; Hubert and Whitney, 1971) to those involving very advanced photogrammetry and satellite imagery analysis in recent times for obtaining CMVs with higher precision (Schmetz et al., 1993; Velden et al., 1997; Kishtawal et al., 2009; Deb et al., 2015; Kaur et al., 2014 and references therein). First level unrefined knowledge about a cloud element can be obtained from the cloud top temperatures, retrieved by Thermal infrared (IR) channel. This is the most commonly used means for CMV estimation, even to this day. However, tracking of low-level clouds $(>700 \mathrm{hPa})$ will be difficult with IR measurements, because the low cloud top apparent temperature becomes so close to the surface temperature that the images lack contrast between the cloud 
and ground levels. Also, the geostationary satellites observe only cloud tops and, therefore, may not be able to detect the multilayered clouds, i.e., for instance a low-level cloud located beneath a high-level cloud.

In this regard, ground-based instrumentation with a large field of view would augment satellite cloud observations (Seiz et al., 2002; Pfister et al., 2003; Souza-Echer et al., 2006; Smith and Toumi, 2008; Liu et al., 2013, Klebe et al., 2014). Such augmentation improves vertical distribution of clouds, albeit at the measurement locations. These sky-imaging devices (eg., Whole-sky imager, Total-sky imager, All-sky imager, etc.) are automatized to achieve realtime hemispheric sky images and cloud fraction (Long et al., 2006; Yang et al., 2012; Kazantzidis et al., 2012).

Among these imagers, the airglow imager is designed primarily for monitoring emissions from the mesosphere and lower thermosphere (MLT) with good spatial and temporal resolutions. The invent of commercial solid state imaging arrays in the 1980s revolutionized airglow imaging observations and in resolving many technical issues in the image processing, such as long-lasting bands, transient short scale ripples, superimposed transversely propagating waves, airglow depletions (Taylor et al., 1995; Batista et al., 2000) and MLT dynamics, such as mesospheric wave signatures and gravity wave seeding of equatorial plasma bubbles (Taori et al., 2013 and references therein). Since, it is an optical device; the measurements are confined only to clear-sky and new moon periods. Nevertheless, its capability to observe clouds on a continuous basis provides an opportunity to derive the CMVs.

The main aim of the present article is to demonstrate the capability of an airglow imager, developed recently at National Atmospheric Research Laboratory (NARL), Gadanki $\left(13.45^{\circ} \mathrm{N}, 79.18^{\circ} \mathrm{E}\right)$, for deriving the CMVs, thereby extending its utilization to the lower atmosphere. In this article, an attempt has been made to adopt the advanced photogrammetry, image processing techniques and satellite CMV retrieval algorithms and implement on ground-based optical imager measurements to obtain the CMVs. The paper includes the following six sections: a description of the instrumentation and database (Sect. 2), study region (Sect. 3), the algorithm and its implementation on a case study (Sect. 4) and validation of the technique (Sect. 5). The strengths and limitations of the technique employed here are also discussed in Sect. 5 . The results are summarized in Sect. 6.

\section{Instrumentation and Database}

The cloud imageries used in the present study are obtained from an airglow imager located at Gadanki. The imager uses a circular medium format F/4 Mamiya fish eye lens having a focal length of $24 \mathrm{~mm}$. At peak wavelengths of 558 and $630 \mathrm{~nm}$, it measures mesospheric $\mathrm{O}\left({ }^{1} \mathrm{~S}\right)$ and thermospheric $\mathrm{O}\left({ }^{1} \mathrm{D}\right)$ emissions, respectively, while a wideband
800-900 nm filter for mesospheric $\mathrm{OH}^{*}$ emission. For observing clouds, $\mathrm{OH}^{*}$ filter is employed due to its high sensitivity in near infrared region. The exposure time for various filters is dependent on the compromise among the background luminosity, interference filter transmission and actual airglow brightness. At present, exposure time for $\mathrm{OH}^{*}$ filter is $16 \mathrm{~s}$, however, as the time integration for $\mathrm{O}\left({ }^{1} \mathrm{~S}\right)$ and $\mathrm{O}\left({ }^{1} \mathrm{D}\right)$ is $110 \mathrm{~s}$ each, the cadence time for capturing the $\mathrm{OH}^{*}$ (i.e., cloud images) is $4 \mathrm{~min}$. These optical emissions are collimated through a series of Plano-convex lens and are passed through temperature controlled interference filters. The filtered rays are converged on the charge-coupled device (CCD) detector which is a back illuminated CCD chip with $1024 \times 1024$ square pixels of $13.3 \mu \mathrm{m}$ size, $100 \%$ fill factor and 16 bit depth. The intensity images thus captured are subjected to a $2 \times 2$ pixel binning for making an effective $512 \times 512$ super-pixels image with enhanced signal-to-noise ratio (SNR). The final images are stored in portable network graphical mode (PNG format). More technical details of the imager can be found in Taori et al. (2013).

The cloud observational data by airglow imager are augmented with a variety of other data sets, like a RayleighMie lidar (RML) and boundary layer lidar (BLL) for obtaining the height of the cloud, Global Positioning System (GPS) radiosonde-derived winds for building the wind climatology for the study region, and mesosphere-stratospheretroposphere (MST) radar-derived winds for validating the derived CMVs. The Rayleigh-Mie lidar has been in operation since 1998 at NARL and is extensively used for understanding cirrus clouds and mesospheric dynamics (Raghunath et al., 2000; Siva Kumar et al., 2001). It is a monostatic biaxial system which uses Neodymium: Yttrium Aluminium Garnet (Nd:YAG) laser as light source and two telescopes (35 and $70 \mathrm{~cm}$ diameter telescopes for Mie and Rayleigh backscatter returns, respectively) as receivers. The transmitter part consists of laser source at the second harmonic of $532 \mathrm{~nm}$ with a maximum energy of about $550 \mathrm{~mJ}$ per pulse. The laser operates at a temporal resolution of $\sim 1 \mathrm{~min}$. Data sets originated from a micro-pulsed BLL are also considered to fill the measurement gaps during the analysis period (Bhavanikumar et al., 2006).

For building the climatology of winds for the study region, 6 years (2007-2012) of GPS radiosonde measurements (Väisälä RS-80, RS-92 and Meisei RS-01GII) at $\sim$ 12:00 universal time (UT) (17:30 Indian standard time (IST)) are used. While developing the climatology, several quality checks have been done on the data to remove spurious outliers, if any exist, following Tsuda et al. (2006). First, the median and standard deviation (SD) of winds for each season are generated. Each profile in this season is then checked for seasonal consistency, i.e., whether or not it falls within 1 SD of median profile. Profiles that are consistent with the seasonal pattern (i.e., those satisfy the above condition) are only considered further for developing the climatology of zonal and meridional winds. 
The MST radar at Gadanki is a highly sensitive pulsecoded coherent VHF phased array radar, operating at $53 \mathrm{MHz}$ with a peak power aperture product of $3 \times 10^{10} \mathrm{Wm}^{2}$. Complete technical and system specifications of the MST radar are given in Rao et al. (1995). The routine operation of MST radar for troposphere employs six beams for obtaining winds and turbulence parameters at $4 \mathrm{~min}$ and $150 \mathrm{~m}$ temporal and vertical resolutions, respectively. Important specifications of MST radar and different types of lidars are given in Table 1.

Though the above remote sensing instruments are in operation for more than a year, simultaneous measurements of all instruments are available only for few days (7 days) for the following reasons. During the rain, it is not possible to operate both the airglow imager and the lidar. The laser beam cannot penetrate the low-level thick clouds and therefore is generally switched off whenever the low cloud persists. On many days, these instruments are in operation for some other experiment in a different mode. For instance, the airglow imager is in operation for MLT studies or MST radar is in operation for ionosphere or convection studies. Since the present article mainly aims to demonstrate the applicability of a satellite technique to a ground-based remote sensing device for deriving CMVs, the number of existing cases (7 days) is sufficient.

\section{Study region and background meteorology}

Gadanki ( $\sim 375$ m a.s.l.) is located in a remote tropical environment in southern peninsular India, at about $90 \mathrm{~km}$ away from the east coast (Fig. 1). It is located in a complex hilly terrain with hill heights varying in the range of 300$1000 \mathrm{~m}$. This region receives rainfall from two major monsoon seasons, namely southwest monsoon (June-September) and northeast monsoon (October-December), besides premonsoon/summer (March-May) thunderstorms (Rao et al., 2009). Nevertheless, it receives an annual rainfall of only $\sim 750 \mathrm{~mm}$, as it is in the rain shadow region (east of Western Ghats). But different types of clouds, originated from a variety of processes, pass over this location frequently (Gadanki is covered with clouds for about $60-70 \%$ of time) (Fig. 1).

Since a priori climatological wind information minimizes the error in retrieved CMVs, wind climatology is built from 6 years of GPS radiosonde observations. Figure 2 shows vertical profiles of mean zonal and meridional winds (solid line) along with standard deviation (error bars) and maximum and minimum (dash-dot lines) winds within the season. Clearly, strongest winds (predominantly easterlies) are observed during the main rainy season for this region, southwest monsoon, in the upper troposphere. These strong winds, popularly known as tropical easterly jet (TEJ), with a peak at $16 \mathrm{~km}$ are an integral part of monsoon circulation. The predominant occurrence of cirrus during the monsoon season is ascribed partly to TEJ, which sweeps the cirrus from neighboring deepest convective regions and spreads over the entire Indian peninsula (Das et al., 2011). Although the mean zonal

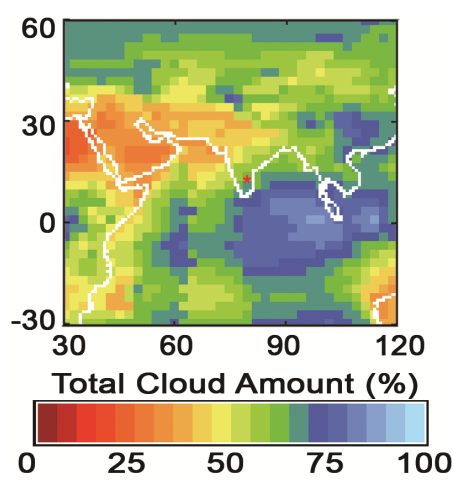

Figure 1. Average cloud cover (in terms of $\%$ of occurrence) over India. The cloud cover data are generated by International Satellite Cloud Climatology Project (ISCCP) from the day and night measurements of polar orbiting satellites made during 1983-2009. The star denotes the location of Gadanki $\left(13.45^{\circ} \mathrm{N}, 79.18^{\circ} \mathrm{E}\right)$. (Courtesy: http://isccp.giss.nasa.gov; reference for ISCCP data product descriptions: Rassow and Schiffer, 1999.)

wind is small in other seasons, often it exceeds $15 \mathrm{~m} \mathrm{~s}^{-1}$ during the winter and early summer, mainly due to the intensification of upper tropospheric subtropical troughs. The meridional winds are generally weak with monthly mean values $<5 \mathrm{~m} \mathrm{~s}^{-1}$. The monthly mean meridional velocities show southerlies in the middle and upper troposphere in all seasons, except for the monsoon. From the range of wind variation (minimum to maximum winds) and the standard deviation, it is clear that the winds are steady and strong during the monsoon season. On the other hand, the winds vary considerably in other seasons, even they change the direction.

\section{Description of the algorithm and its application on a case study (17 April 2012)}

This section describes the method adopted for the retrieval of cloud motion with the help of airglow imager data collected on 17 April 2012. In fact, a variety of retrieval techniques for CMVs using satellite brightness temperatures (from thermal satellite imagery) are now available (Kishtawal et al., 2009; Deb et al., 2015; Kaur et al., 2014 and references therein). The present algorithm adopts one such retrieval technique for the estimation of CMVs and modifies it to suit airglow imager observations. In the following subsections, the major processing steps involved in the algorithm are discussed in detail.

1. Image processing to remove the noise, enhancing the image and identifying the target cloud

2. Estimation of cloud height and pixel width

3. Estimation of cloud movement using a cross-correlation technique and CMVs. 
Table 1. Specifications of the MST radar and different lidars for routine operations.

\begin{tabular}{lll}
\hline $\begin{array}{l}\text { Parameter } \\
\text { MST Radar }\end{array}$ & Value & \\
\hline Operating frequency & $53 \mathrm{MHz}$ & \\
Pulse width & $16 \mu \mathrm{s}$ & \\
Inter pulse period & $1 \mathrm{~ms}$ & \\
Beam width & $3^{\circ}$ & \\
Beam scanning strategy & six beams: two in zenith and four in off-zenith directions & \\
Tilt angle & $10^{\circ}$ & \\
Temporal resolution & $\sim 4 \mathrm{~min}$ for one scan cycle $(6$ beams $)$ & Boundary layer lidar \\
Height resolution & $150 \mathrm{~m}$ & $532 \mathrm{~nm}$ \\
\hline Lidar & & $150 \mathrm{~mm}$; Cassegrain \\
& Rayleigh-Mie lidar & $25 \mu \mathrm{J}$ \\
\hline Operating wavelength & $532 \mathrm{~nm}$ & $2.5 \mathrm{KHz}$ \\
Receiver telescope & $350 \mathrm{~mm}$; Schmidt-Cassegrain & 1500 \\
Energy per pulse & $550 \mathrm{~mJ}$ & $30 \mathrm{~m}$ \\
Pulse repetition rate & $50 \mathrm{~Hz}$ & $4 \mathrm{~min}$ \\
Number of bins & 1024 & \\
Height resolution & $300 \mathrm{~m}$ & $1 \mathrm{~min}$ \\
Temporal resolution & & \\
\hline
\end{tabular}
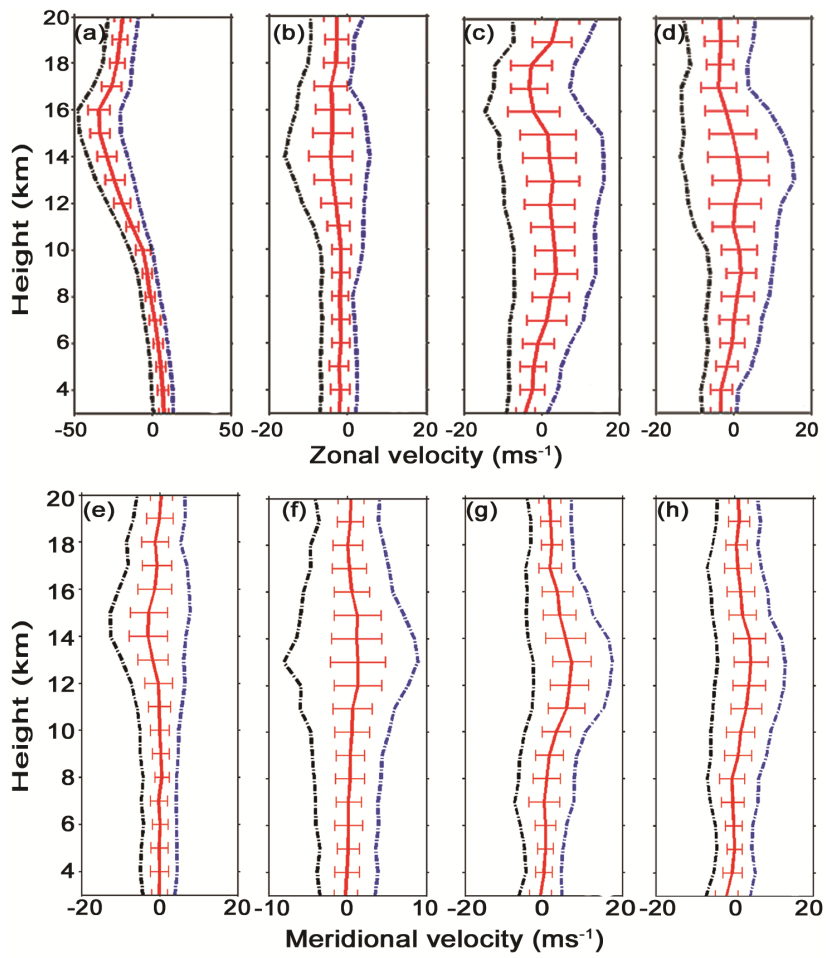

Figure 2. The seasonal mean (a-d) zonal and (e-h) meridional winds (solid line) for southwest monsoon, northeast monsoon, winter and summer seasons, respectively. Also shown are the standard deviation as error bars and the range of wind velocities (minimum and maximum winds as dash dot lines) within the season.
Figures 3-5 show the output of each of the above processing steps.

\subsection{Image processing and target cloud identification}

The first and most important step of the algorithm is to process the image for better identification of the target cloud. The image processing involves correction of coordinates, removal of noisy structures (like stars), improving the image contrast for better visualization of target elements (clouds in our case) (Fig. 3). The original $512 \times 512$ pixel images are cropped to $256 \times 256$ pixels to remove the pixels that are affected by the housing of the airglow imager (Taori et al., 2013) (Fig. 3b). The cropped image corresponds to $90^{\circ}$ circular field of view. During the measurements, the boundaries of the instrument roof were marked by the directions identified by the magnetic compass, which appears to be reversed along N-S directions in the raw images. Hence the cropped images are flipped vertically so as to correct for geographical coordinates. We enhanced the image contrast by using the gray-level histogram method (Otsu, 1979). This involves mapping the intensity values on gray scale image to new values such that $1 \%$ of data is saturated at low and high intensities of the image. This increases the contrast of the output image (Fig. 3c). The appearance of stars and other galactic objects in the image caps the cloud structures and decreases the image SNR. These "noisy" structures need to be removed before identifying the target cloud(s) in the image. These bright objects (stars and clouds) are detected using an edge detection technique.

Edge detection is one of the very basic concepts used for image processing to identify the target elements. The edge 

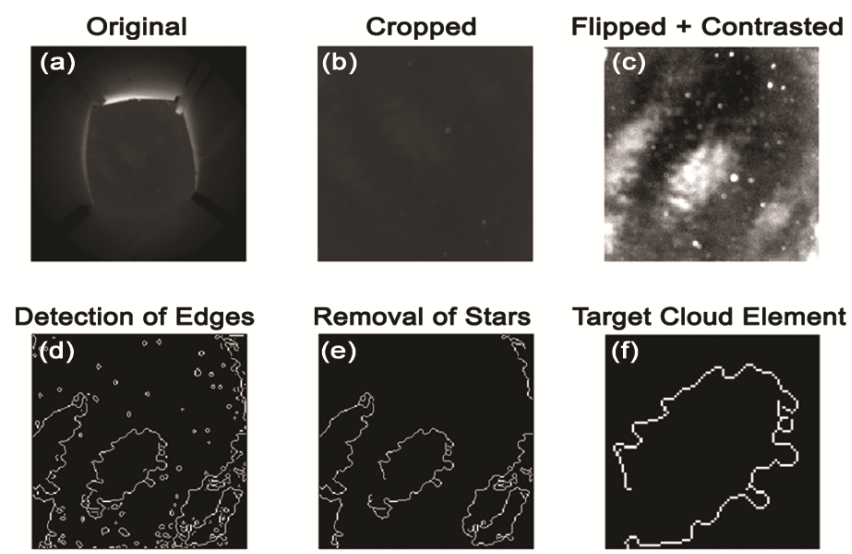

Figure 3. Various processing steps involved in identifying the target cloud. (a) The original image having $512 \times 512$ pixels, (b) the cropped image having $256 \times 256$ pixels, (c) the image corrected for geometric coordinates and later enhanced using the gray-level histogram method, (d) the contours of high intensity identified by using the Canny method of edge detection, (e) the cleaned cloud image after the removal of stars and noisy structures and (f) the target cloud.

detection techniques are basically of two types; gradientbased and Laplacian- based techniques (Argyle, 1971; Grimson and Hildreth, 1985; Torre and Poggio, 1986; Canny, 1986). While the former detects the edges from the gradient (first derivative) of pixel intensities, the latter detects edges from zero crossings in the second-order derivative of pixel intensities. Canny edge-detection method (Canny, 1986), which follows the gradient method with the following optimization criteria, has been used in the present study.

1. Minimizing the incorrect marking of non-existing edge points and missing the real edge points, i.e., good detection or low error rate.

2. The distance between the detected and the actual edge pixels should be minimized, i.e., good localization.

To avoid small statistical fluctuations in pixel intensities being detected as target elements or noisy structures, the image is smoothed using the Gaussian smoothing filter. The algorithm then estimates the spatial derivative of pixel intensities and this gradient matrix is subjected to hysteresis analysis to identify the edges. Hysteresis uses two thresholds, a high and a low. Any pixel in the gradient matrix that has a value greater (lower) than high (low) threshold is identified as (not) an edge pixel. The pixel is also treated as an edge pixel, if it has a value between the two thresholds and is connected to an edge pixel. Later contiguous edge pixels are connected to generate contours of target objects (clouds, stars, etc.) with high intensities overlaid on the background of low intensities (Fig. 3d).

Since stars and other noisy structures appear as small objects in Fig. 3c, they can be removed by imposing a threshold for number of pixels. In the present study, the contours of large gradient (or simply target objects) having pixels less than 1000 are considered as noisy structures or stars and are removed for further analysis (Fig. 3e). The above threshold is not arbitrary, rather chosen by examining several images. The target cloud is then identified from the cleaned image (after the removal of noisy structures). In the present study, the target cloud is identified as the cloud that have the highest gradient value and number of pixels (Borde and García-Pereda, 2014) and at the same time should be isolated and persists for some time (at least in the next image). Further, priority is given to that cloud (if more than one cloud satisfies the above criteria) which is at the center of the image. This condition is important because the cloud height is later estimated from lidar measurements made at Gadanki. The center of the image in geometric coordinates roughly corresponds to the location of Gadanki.

\subsection{Estimation of cloud height and pixel width}

Estimation of cloud base height is an important step in the extraction of CMVs for two reasons, (i) the pixel width and thereby the distance traveled by the cloud is estimated from the height of cloud base and (ii) the estimated CMV is assigned to this height. Any error in the estimation of cloud base height will lead to significant errors in both pixel width and velocity of cloud (Park et al., 2012; Borde and GarcíaPereda, 2014 and references therein). Since height information is very crucial, a lidar, which provides the cloud information at a resolution of $30 \mathrm{~m}$, is employed in the present study. The photon counts are range corrected, and the height of their maximum positive vertical gradient (above $5 \mathrm{~km}$ ) is identified in each profile and is treated as the cloud base height (CBH). The threshold of $5 \mathrm{~km}$ is chosen to avoid confusion caused by the gradients due to aerosol layers. The CBH identified from successive vertical profiles of photon counts are examined for their continuity. In other words, the successive $\mathrm{CBH}$ measurements should not vary by more than $300 \mathrm{~m}$. Figure $4 \mathrm{a}$ shows the temporal variation of $\mathrm{CBH}$ retrieved from the photon counts of boundary layer lidar during 21:40-22:04 IST. Once the height of cloud is known, the estimation of pixel width is simple. Since the angle subtended by the cropped image at the location of measurement is $90^{\circ}$, the pixel width at different altitudes can be estimated by a simple mathematical relation,

Pixelwidth $=R \cdot \tan (45) / 128$,

where $R$ is the height of cloud base. The vertical variation of pixel width estimated from the above relation is shown in Fig. 4b. The images need to be unwrapped to convert angular scales into linear scales for estimating the pixel width (in $\mathrm{m}$ ). To estimate the lens curvature effects, an experiment has been carried out, in which grids with known scale sizes were imaged. Within a $90^{\circ}$ field of view (out of full field of view), the scale of pixel size increases from 1 at the center to 1.036 at the edges (Sivakandan et al., 2015). It is in good 

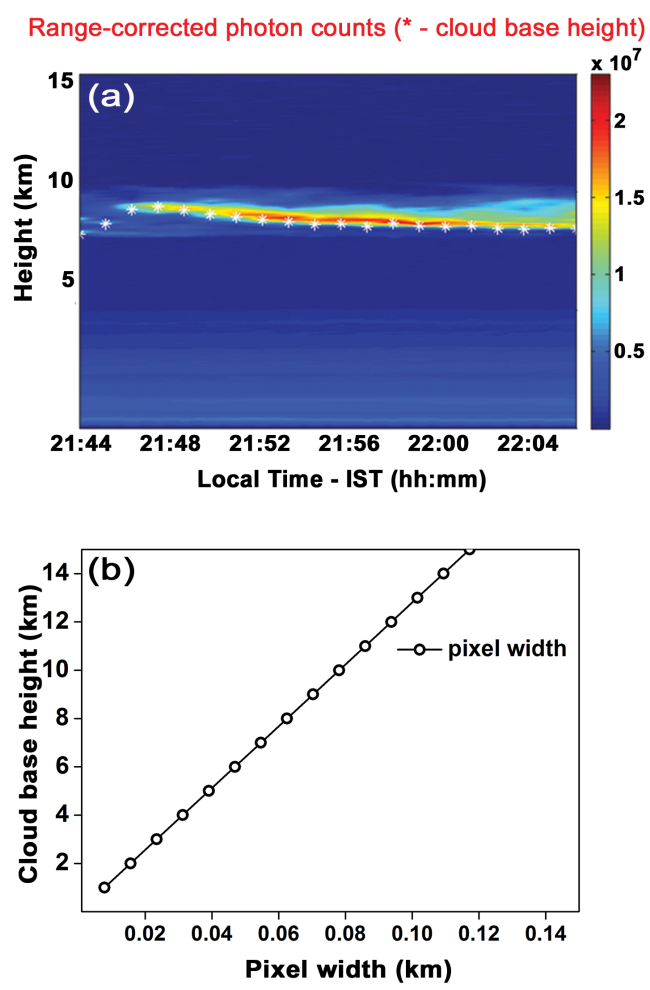

Figure 4. (a) Height-time variation of range corrected photon count (shading) showing the $\mathrm{CBH}$ variation (white stars) on April 17, 2012. (b) Vertical profile of pixel width calculated using the $\mathrm{CBH}$.

agreement with Kubota et al. (2001), who showed that the maximum effect arising from lens curvature and Van-Rhijn factor is $<0.9$.

\subsection{Tracking the target cloud and the estimation of CMV}

Tracking the target cloud is very essential for the estimation of CMV. Three factors are crucial in tracking the target cloud and dictate the accuracy of CMV: search window, temporal resolution between the images and identification of the same cloud in successive images. To reduce the computational load and to avoid other clouds or noisy structures, if any remain, entering into the area of interest; it is a common practice to track the target cloud in a smaller search domain in successive images. While the large target window allows other unwanted noisy structures enter into the search domain, too small window increases false alarms (Bresky et al., 2012). Conventionally, wind guess (WG) information supplements this exercise and to set the coordinates of smaller windows in the latter image before matching (Velden et al., 1997; Bedka and Mecikalski, 2005; Bresky et al., 2012). In the present study, the horizontal wind climatology discussed in Sect. 3 is used to set the search window. The spatial search window is fixed based on the maximum wind speed (at the cloud height) obtained from wind climatology and the time inter-
21:44

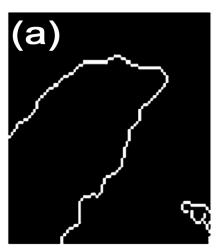

21:48

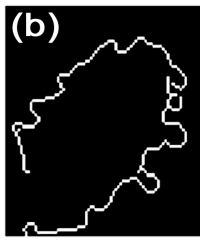

21:52

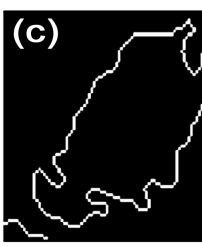

21:56

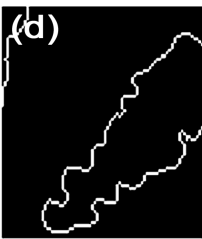

Figure 5. Sequential images of the detected target cloud on 17 April 2012 (Time as per IST in hh:mm format).

val between the successive images. For instance, the cloud would move $2.4 \mathrm{~km}$ in the presence of $10 \mathrm{~m} \mathrm{~s}^{-1}$ wind speed in $4 \mathrm{~min}$. Therefore, a search window length of 30 pixels is required if the target cloud is at $10 \mathrm{~km}$ altitude. The time interval between successive images has a significant impact on the quality of the derived CMVs. Though satellites generally use $30 \mathrm{~min}$ intervals to derive the CMVs, earlier studies have shown that a temporal gap of $5 \mathrm{~min}$ for $1 \mathrm{~km}$ pixel size would produce largest number of valid motion vectors (Garcia-Pereda and Borde, 2014). The time interval between the successive images in the present study is $4 \mathrm{~min}$, which is nearly equal to the optimum time gap suggested by GarciaPereda and Borde (2014). Identification of the same target cloud in successive images is very important. Since the airglow imager is a vertically up-looking system with a limited field of view $\left(90^{\circ}\right)$, there is possibility that it identifies two different clouds in successive images (for example, a low cloud can suddenly mask a high cloud). It is therefore required to use a proper pattern recognition method to estimate the cloud motion. In the present study $2 \mathrm{D}$ cross correlation method is employed for this purpose. The images were discarded if the correlation coefficient obtained from the crosscorrelation of two successive images is $<0.5$.

Figure 5 shows a typical example of identified target cloud in four successive images on 17 April 2012. The target cloud imageries are cross-correlated to obtain the lag/lead at the maximum correlation. Though it is possible to obtain the lag/lead information from two successive images, it may be worthwhile, wherever possible, to consider many such correlation pairs for consistency (Deb et al., 2015). Figure 6 depicts time sequence of normalized cross-correlated images. From these images, the lag/lead of the maximum correlation pixel in both east-west ( $x$ axis) and north-south ( $y$ axis) planes is identified. The distance traveled by the cloud in $x$ and $y$ directions is estimated from the number of pixels displaced from 0 and pixel width, which is obtained from lidar-CBH (Fig. 4). The zonal and meridional velocities are then estimated simply by dividing the distance traveled in $x$ and $y$ planes, respectively, with time interval between the successive images (4 min in our case). During the observational period of $20 \mathrm{~min}$, the $\mathrm{CBH}$ is found to be nearly constant (variations are within $300 \mathrm{~m}$ ), whereas the zonal and meridional wind velocities varied from 1.49 to $3.71 \mathrm{~m} \mathrm{~s}^{-1}$ 


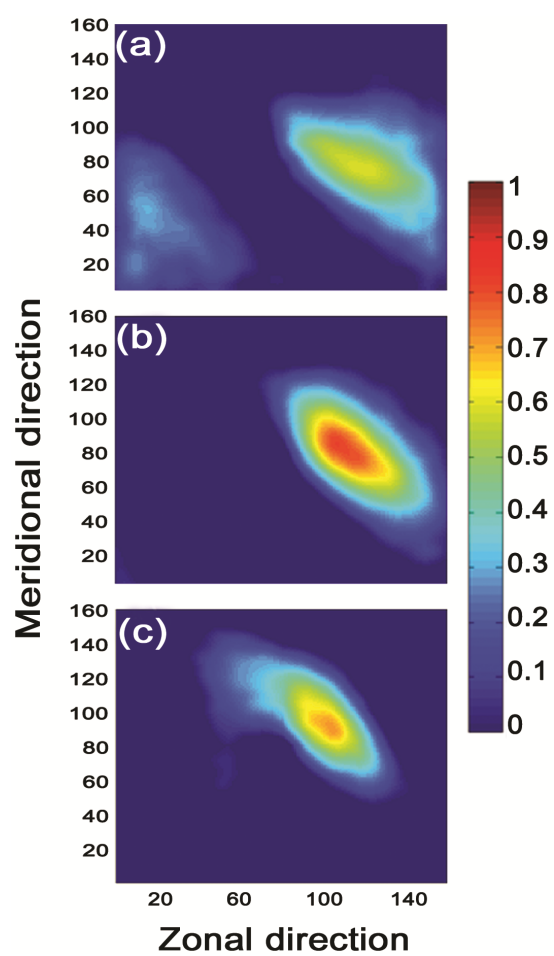

Figure 6. Images showing the output of 2-D cross-correlation between the sequential images (a) 21:44-21:48 IST (b) 21:4821:52 IST and (c) 21:52-21:56 IST.

and from -0.89 to $-4.86 \mathrm{~m} \mathrm{~s}^{-1}$, respectively. The velocity resolution of the wind vector derived with this method depends on the accuracy with which one derives the displacement of the cloud. Since it depends on the height-dependent pixel width (Fig. 4b), the velocity resolution also varies with height. For instance, the resolution varies from $0.16 \mathrm{~m} \mathrm{~s}^{-1}$ at $5 \mathrm{~km}$ to $0.32 \mathrm{~m} \mathrm{~s}^{-1}$ at $10 \mathrm{~km}$.

\section{Discussion}

It is important and necessary to evaluate the performance of any new algorithm or technique or instrument as it gives credibility to the final product. A similar exercise has been done, in which CMVs derived from all the cases were compared against a reference. In the present study, MST radarderived winds measured simultaneously are taken as a standard reference for comparison. Several intense campaigns have been conducted to quantify the accuracy of Indian MST radar-derived winds by comparing them with radiosondederived winds (considering them as the truth). The accuracy of MST radar-derived winds is found to be about $1-2 \mathrm{~m} \mathrm{~s}^{-1}$, depending on the balloon drift from the radar site. Figure 7 shows the comparison of zonal and meridional winds as derived by both airglow imager (CMVs) and MST radar. Clearly, the airglow imager-derived winds show good correspondence with radar-derived winds in both zonal and merid-
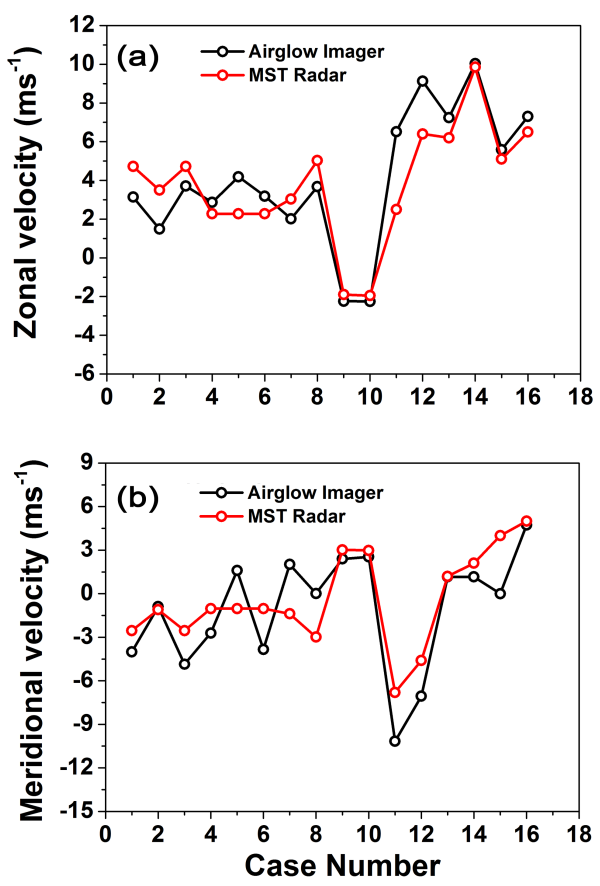

Figure 7. Comparison of (a) zonal and (b) meridional wind velocities derived by airglow imager and MST radar.

ional components with similar variations. Even the wind magnitude matches fairly well between the two data sets with root mean square error (RMSE) values $<2.25 \mathrm{~m} \mathrm{~s}^{-1}$. The agreement is much better in the zonal component (RMSE is 1.60) than in meridional (RMSE is 2.24). It appears from Fig. 7 that there is no bias in airglow imager-derived winds, and the difference between the wind estimates is due to statistical error.

Although the performance of the algorithm is fairly good and the technique has several advantages (like better temporal resolution, pixel resolution, etc.), it also suffers with the following drawbacks. (i) Since the airglow imager is an optical instrument, observations are limited to non-rainy days. (ii) Though the imager detects the target cloud and tracks it, but it will not be able to estimate the height of the target cloud. As discussed above, CBH information is crucial not only for assigning the derived winds to that height, but also to estimate the pixel width (Fig. 4b) and thereby the cloud displacement for CMV estimation. Though we used a lidar for obtaining $\mathrm{CBH}$ as those measurements are readily available, it is a costly proposition. A ceilometer would suffice the purpose. (iii) The limited field of view imposes a limit on the applicability of the algorithm to certain clouds. Since the algorithm needs isolated clouds for tracking, the clouds with dimensions much less than the field of view of the imager can only be used as target clouds. (iv) As the cloud is not a frozen body but an evolving system, the cloud boundaries do change with time. Since the time interval between two successive images is only $4 \mathrm{~min}$, the changes may not be signifi- 
cant and ignored. But during a period of few 10s of minutes, the periods typically used in satellite retrievals of CMVs, the cloud appearance can change significantly (Fig. 5). It reiterates the requirement of small interval between the successive images and proper selection of target cloud (rapidly evolving clouds should not be considered as target clouds) for better extraction of CMVs.

\section{Summary}

The present study utilizes the $865 \mathrm{~nm}$ channel of the airglow imager to take high-resolution images of clouds. These bi-products of airglow imager have been used to estimate CMVs by adopting advanced satellite retrieval algorithms and implementing them, after suitable modifications, on airglow imager-derived cloud imageries. The present article describes an algorithm and implementation steps adopted while deriving the CMVs. The images are first processed with advanced image processing tools and later detected the target cloud within the image. Climatological wind profiles developed from GPS radiosonde data have been utilized for fixing a proper search window to minimize the errors. The tracking of target cloud from sequential images has been done by subjecting 2-D cross-correlation on the successive images. The displacement of cloud due to the horizontal wind in both eastwest and north-south planes is identified from the lead/lag position of maximum correlation. To convert the cloud displacement from number of pixels to distance and to assign the derived winds to a height, accurate estimation of cloud height is essential. High-resolution measurements of collocated lidar were used for this purpose. The derived winds are then evaluated against a reference (MST radar-derived winds in the present study). Good correspondence is seen between the two measurements of wind (airglow imager and MST radar), as both of them show similar variation. The magnitude of wind also matches well with the reference wind (obtained by the MST radar) with a small RMSE $\left(<2.4 \mathrm{~m} \mathrm{~s}^{-1}\right)$. The strengths and limitations of the algorithm are highlighted with possible solutions, wherever required.

Acknowledgements. The ISCCP D2 image (Fig. 1) is generated from the International Satellite Cloud Climatology Project (web site http://isccp.giss.nasa.gov), maintained by the ISCCP research group at the NASA Goddard Institute for Space Studies, New York.

Edited by: M. Nicolls

\section{References}

Argyle, E.: Techniques for edge detection, Proc. IEEE, 59, 285-286, 1971.

Batista, P. P., Takahashi, H., Gobbi, D., and Medeiros, A. F.: First airglow all sky images at $23^{\circ} \mathrm{S}$, Adv. Space. Res., 26, 925-928, 2000.
Bedka, K. and Mecikalski, J. R.: Application of satellite derived atmospheric motion vectors for estimating Mesoscale flows, J. Appl. Meteorol., 44, 1761-1772, 2005.

Bhavanikumar, Y.: Portable lidar system for atmospheric boundary layer measurements, Opt. Eng., 45, 076201, doi:10.1117/1.2221555, 2006.

Borde, R. and García-Pereda, J.: Impact of wind guess on the tracking of atmospheric motion vectors, J. Atmos. Ocean. Tech., 31, 458-467, 2014.

Bresky, W. C., Daniels, J. M., Bailey, A. A., and Wanzong, S. T.: New methods toward minimizing the slow speed bias associated with atmospheric motion vectors, J. Appl. Meteorol. Clim., 51, 2137-2151, 2012

Canny, J. F.: A computational approach to edge detection, IEEE T. Pattern Anal., PAMI-8, 679-697, 1986.

Das, S. K., Chiang, C.-W., and Nee, J.-B: Influence of tropical easterly jet on upper tropical cirrus: An observational study from CALIPSO, Aura-MLS, and NCEP/NCAR data, J. Geophys. Res., 116, D12204, doi:10.1029/2011JD015923, 2011.

Deb, S. K., Kishtawal, C. M., Kaur, I., Pal, P. K., and Kiran Kumar, A. S.: Assessment of a new quality control technique in the retrieval of atmospheric motion vectors, Meteorol. Appl., 22, 178186, 2015.

Escrig, H., Batlles F. J., Alonso J., Baena, F. M., Bosch, J. L., Salbidegoitia, I. B., and Burgaleta, J. I.: Cloud detection, classification and motion estimation using geostationary satellite imagery for cloud cover forecast, Energy, 55, 853-859, doi:10.1016/j.energy.2013.01.054, 2013.

Garcia-Pereda, J. and Borde, R.: Impact of the tracer size and the temporal gap between images in the extraction of atmospheric motion vectors, J. Atmos. Ocean. Tech., 30, 1171-1179, doi:10.1175/JTECH-D-13-00235.1, 2014.

Glantz, P.: Satellite retrieved cloud optical thickness sensitive to surface wind speed in the subarctic marine boundary layer, Environ Res. Lett., 5, 1-5, doi:10.1088/1748-9326/5/3/034002, 2010.

Grimson, W. E. and Hildreth, E. C.: Comments on Digital step edges from zero crossings of second directional derivatives, IEEE T.. Pattern Anal., PAMI-7, 121-129, 1985.

Hubert, L. and Whitney Jr., L. F.: Wind estimation from geostationary-satellite pictures, Mon. Wea. Rev., 99, 665-672, 1971.

Hutchison, K. D., Hardy, K. R., and Gao, B. C.: Improved detection of optically thin cirrus clouds in nighttime multispectral meteorological satellite using total integrated water vapor information, J. Appl. Meteorol., 34, 1161-1168, 1995.

Izawa, T. and Fujita, T.: Relationship between observed winds and cloud velocities determined from pictures obtained by the ESSA 3, ESSA 5 and ATS-I satellites, Space Research IX, Amsterdam, North-Holland Publ. Co., 571-579, 1969.

Jolivet, D. and Feijt, A. J.: Cloud thermodynamic phase and particle size estimation using the 0.67 and $1.6 \mu \mathrm{m}$ channels from meteorological satellites, Atmos. Chem. Phys. Discuss., 3, 4461-4488, doi:10.5194/acpd-3-4461-2003, 2003.

Kaur, I., Deb, S. K., Kishtawal, C. M., Pal, P. K., and Kumar, R.: Atmospheric motion vector retrieval using improved tracer selection algorithm, Theor. Appl. Climatol., 119, 299-312, doi:10.1007/s00704-014-1115-1, 2014.

Kazantzidis, A., Tzoumanikas, P., Bais, A. F., Fotopoulos, S., and Economou, G.: Cloud detection and classification with the use 
of whole-sky ground-based images, Atmos. Res., 113, 80-88, doi:10.1016/j.atmosres.2012.05.005, 2012.

Kishtawal, C. M., Deb, S. K., Pal, P. K., and Joshi, P. C.: Estimation of atmospheric motion vectors from Kalpana-1 imagers, J. Appl. Meteorol. Clim., 48, 2410-2421, 2009.

Klebe, D. I., Blatherwick, R. D., and Morris, V. R.: Ground-based all-sky mid-infrared and visible imagery for purposes of characterizing cloud properties, Atmos. Meas. Tech., 7, 637-645, doi:10.5194/amt-7-637-2014, 2014.

Kubota, M., Fukunishi, H., and Okano, S.: Characteristics of medium- and large-scale TIDs over Japan derived from O1630 nm nightglow observation, Earth Planets Space, 53, 741751,2001

Leese, J. A., Novak, C. S., and Clark, B. B.: An automated technique for obtaining cloud motion from Geosynchronous satellite data using cross correlation, J. Appl. Meteorol., 10, 118-132, 1971.

Liu, L., Sun, X.-J., Gao, T.-C., and Zhao, S.-J.: Comparison of cloud properties from ground-based infrared cloud measurement and visual observations, J. Atmos. Ocean. Tech., 30, 1171-1179, doi:10.1175/JTECH-D-12-00157.1, 2013.

Long, J. M., Sabburg, J., Calbo, and Pages, D.: Retrieving cloud characteristics from ground-based daytime color all-sky images, J. Atmos. Ocean. Tech., 23, 633-652, 2006.

Menzel, W. P.: Cloud tracking with satellite imagery: from the pioneering work of Ted Fujita to the present, B. Am. Meteorol. Soc., 82, 33-47, 2001.

Otsu, N.: A Threshold selection method from gray-level histograms, IEEE T. Syst. Man Cyb., 9, 62-66, 1979.

Park, J.-H., Ou, M.-L., Kim, S., and Cho, H.: Sensitivity of satellitederived wind retrieval over cloudy scenes, IEEE T. Geosci. Remote., 50, 2063-2073, 2012.

Pfister, G., McKenzie, R. L., Liley, J. B., Thomas, A., Forgan, B. W., and Long, C. N.: Cloud coverage based on all-sky imaging and its impact on surface solar irradiance, J. Appl. Meteorol., 42, 1421-1434, 2003.

Raghunath, K., Bhavanikumar, Y., Sivakumar, V., Rao, P. B., Mizutani, K., Aoki, T., Yasui, M., and Itabe, T.: Indo-Japanese lidar observations of aerosols over a tropical latitude, Indian J. Radio Space Phys., 25, 239-244, 2000.

Rao, P. B., Jain, A. R., Kishore, P., Balamuralidhar, P., Damle, S. H., and Viswanathan, G.: Indian MST radar 1. System description and sample vector wind measurements in ST mode, Radio Sci., 30, 1125-1138, doi:10.1029/95RS00787, 1995.

Rao, T. N., Radhakrishna, B., Nakamura, K., and Prabhakara Rao, N.: Differences in raindrop size distribution from southwest monsoon to northeast monsoon at Gadanki, Q. J. R. Meteorol. Soc., 135, 1630-1637, 2009.

Rassow, W. B. and Schiffer, R. A.: Advances in understanding clouds from ISCCP, B. Am. Meteorol. Soc., 80, 2261-2288, 1999.
Schmetz, J., Holmlund, K., Hoffman, J., Strauss, B., Mason,B., Gaertner, V., Koch, A., and van de Berg, L.: Operational cloudmotion winds from Meteosat infrared images, J. Appl. Meteorol., 32, 1206-1225, 1993.

Seiz, G., Baltsavias, E. P., and Gruen, A.: Cloud mapping from the ground: Use of Photogrammetric methods, Photogramm. Eng. Remote., 68, 941-951, 2002.

Sivakandan, M., Taori, A., Satishkumar, S., and Jayaraman, A.: Multi-instrument investigation of a mesospheric gravity wave event absorbed into background, J. Geophy. Res., 33, 31503159, doi:10.1002/2014JA020896, 2015.

Siva Kumar, V., Bhavani Kumar, Y., Raghunath, K., Rao, P. B., Krishnaiah, M., Mizutani, K., Aoki, T., Yasui, M., and Itabe, T.: Lidar measurements of mesospheric temperature inversion at a low latitude, Ann. Geophys., 19, 1039-1044, doi:10.5194/angeo-191039-2001, 2001.

Smith, S. and Toumi, R.: Measuring cloud cover and brightness temperature with a ground-based thermal infrared camera, J. Appl. Meteorol. Clim., 47, 683-693, 2008.

Souza-Echer, M. P., Pereira, E. B., Bins, L. S., and Andrade, M. A. R.: A simple method for the assessment of the cloud cover state in high-latitude regions by a ground-based digital camera, J. Atmos. Ocean. Tech., 23, 437-447, 2006.

Taori, A., Jayaraman, A., and Kamalakar, V.: Imaging of mesosphere-thermosphere airglow emissions over Gadanki $\left(13.51^{\circ} \mathrm{N}, 79.21^{\circ} \mathrm{E}\right)$ - first results, J. Atmos. Sol.-Terr. Phy., 93, 21-28, 2013.

Taylor, M. J., Bishop, M. B., and Taylor, V.: All-sky measurements of short period waves imaged in the OI $(556.7 \mathrm{~nm}), \mathrm{Na}$ $(589.2 \mathrm{mn})$ and near IR OH and $\mathrm{O}_{2}(0,1)$ nightglow emission during the ALOHA-93 Campaign, Geophys. Res. Lett., 22, 28332836, 1995.

Thies, B. and Bendix, J.: Satellite based remote sensing of weather and climate: recent achievements and future perspectives, Meteorol. Appl., 18, 262-295, 2011.

Torre, V. and Poggio, T. A.: On edge detection, IEEE T. Pattern Anal., PAMI-8, 187-163, 1986

Tsuda, T., Venkatratnam, M., Kozu, T., and Mori, S.: Characteristics of 10-day Kelvin wave observed with radiosondes and CHAMP/GPS occultation during CPEA campaign (April-May 2004), J. Meteorol. Soc. Jpn., 84A, 277-293, doi:10.2151/jmsj.84A.277, 2006.

Velden, C. S., Hayden, C. M., Nieman, S. J., Menzel, W. P., Wanzong, S., and Goerss, J. S.: Upper-tropospheric winds derived from geostationary satellite water vapor observations, B. Am. Meteorol. Soc., 78, 173-195, 1997.

Yang, J., Weitao, L., Ying, M., and Wen, Y.: An automated Cirrus cloud detection method for a ground-based cloud image, J. Atmos. Ocean. Tech., 29, 527-537, doi:10.1175/JTECH-D-11$00002.1,2012$. 